University of Nebraska - Lincoln

DigitalCommons@University of Nebraska - Lincoln

Textile Society of America Symposium

Proceedings

Textile Society of America

2020

Project to Recover Prehispanic Textile Techniques in Peru: A brief

review, from its initiation to today

Yuki Seo

Follow this and additional works at: https://digitalcommons.unl.edu/tsaconf

Digitalrt of the Art and Materials Conservation Commons, Art Practice Commons, Fashion Design

Commens, Fiber, Textile, and Weaving Arts Commons, Fine Arts Commons, and the Museum Studies

detwerkns

Logo

This Article is brought to you for free and open access by the Textile Society of America at

DigitalCommons@University of Nebraska - Lincoln. It has been accepted for inclusion in Textile Society of America

Symposium Proceedings by an authorized administrator of DigitalCommons@University of Nebraska - Lincoln. 


\title{
Project to Recover Prehispanic Textile Techniques in Peru: A brief review, from its initiation to today
}

\author{
Yuki Seo
}

\section{Textiles in Peru:}

When you first enter the world of Peruvian textiles, that of today or of prehispanic times, you are swept away by its particularity. What general happens is: the more you learn, the stronger your feelings become and, in the end, you realize that you cannot, nor do you wish to, leave this world in which there is an endless amount to learn.

Today hand weavers can be found in every region of Peru; the coastal lowlands, the Andean highlands, and the eastern rainforests. Each region has different fibers according to its climate and fauna. There are artisan spinners, and you can observe dye processes based on the natural dyestuffs used in the traditions of each area. Some communities continue to conserve and recover traditions from colonial and even prehispanic times.

If you observe the historic aspect, textiles from as much as 10000 years ago can be found in a good state of conservation. Peru is one of few countries in the world where ancient textiles are preserved, as in Egypt and China. In the history of Peruvian textiles, each culture abounds in topics to be investigated, and one's curiosity to explore the wisdom of the ancestral weavers is inexhaustible.

I am one of so many who have been ensnared by the textiles of this country.

Peru and Japan, two precedents:

Peru: I began to work as a conservator of prehispanic textiles in 2004, after finishing a three-year program in conservation in Lima, Peru. ${ }^{1}$ I travelled to several archaeological sites in this in order to practice as a conservator of excavated material, while also working and studying. Each project provided a great deal of professional experience and at the same time my questions accumulated regarding contemporary textile work.

The museums conserve and show us diverse textiles with particular techniques. Also, you can find many academic studies about them in any publication about textiles.

When I observed textile work today, the master weavers have tremendous skill, quality and textile knowledge particularly in such techniques as tapestry and warp-faced patterning.

Nonetheless, not many practice the peculiar techniques of the prehispanic era such as the Sprang or Gauze weave of the Chancay and Chimú cultures, discontinuous scaffolded warp and weft, and others.

\footnotetext{
${ }^{1}$ Instituto Superior de Conservación y Restauración Yachay Wasi.
} 
I asked, why is there not a greater connection between prehispanic and contemporary textiles?

Japan: Japan has a prevalent social tendency in which it is common to express respect for tradition. That which is ancient is valued. There is an old word in Japanese, MANEBU, which meant to copy that which is old, that which is good, and the way of the teacher. ${ }^{2}$ This is the origin of the word MANABU in contemporary Japanese, which means to learn. That is to say, to copy that which is old is the first step in learning. ${ }^{3}$

Currently there are several researchers ${ }^{4}$ of prehispanic textiles in Japan. It is curious to note a clear difference between the researchers from other countries and those from this country of the Orient. Most of them investigate prehispanic Peruvian textiles by analyzing their techniques, including replication, and with time they achieve a high level of skill like that shown in the original textile.

Another particularity is that the majority of them do not belong to any academic institution. They investigate individually or sometimes as a group.

While completing my practicum and working in museums in Lima, I had the opportunity to meet two of these researchers, Ms. Yoshie Aoyagi and Ms. Keiko Watanabe, who visited Peru to seek pieces for their investigations. They came almost every year, and I had the good fortune to help them obtain the permits necessary for their research and to accompany them in their fieldwork.

Ms. Yoshie Aoyagi investigates Japanese braiding, "Kumihimo" and also has studied prehispanic and contemporary Andean braiding during 40 years. She belongs to the group of Kumihimo studies under the supervision of Dr. Makiko Tada. ${ }^{5}$ Each year Ms. Aoyagi has come to Peru with her husband and she stayed for a month in Lima and in the provinces, such as Cusco, researching in the museums and she looked for the masters of braiding to learn from them. ${ }^{6}$ Then she created replicas of the pieces when she returned to her country.

\footnotetext{
${ }^{2}$ Yukiko Tsukuda (Koyun), personal communication, 2020.

${ }^{3}$ In the old schools (TERAKOYA) students copied the books of Confucius and Laozi, among other books of ancient China.

${ }^{4}$ Nobuko Kajitani, The Textiles of the Andes: Senshoku no Bi (Kyoto: Kyoto Shoin, Fall 1982), 9-96. Miyako Suzuki Organizational skills and techniques of woven textiles of the Andes (Kyoto, Shikosha, 1999). Chieko Aihara Sprang (Kanagawa, Yupanqui kobo, 2003). https://sites.google.com/site/ypq2aiharaes2/

${ }^{5}$ Faculty at the Kyoto Institute of Technology and director of the International Conference on Braiding. Makiko Tada, "Andean Braids," Comprehensive Treatise of Braids, Vol. II, (Tokyo: Texte, Inc., 2019); Makiko Tado, "Braids of the Andes," Advances in Kumihimo and Fiber Arts: Proceedings of the Fourth International Conference on Braiding Braids 2019, 51-58.

${ }^{6}$ She has written a book about her experience, analysis and replicas: Yoshie Aoyagi, Exploring the Braids of the Andes (Tokyo, Texte, 2020).
} 
Ms. Keiko Watanabe is a specialist in the technique of close knotting, ${ }^{7}$ specifically that of the Paracas culture. ${ }^{8}$ She has carried out interesting studies and has had fine results regarding a knotting technique of the Philippines, and based on this experience, over the past 30 years she has carried out research and made replicas of Paracas knotting. I especially wish to focus on her work, as she is the only person in the world who was able to create replicated samples of Paracas knotting.

We know there have been great number of academic specialists and researchers on Paracas textiles, however, there are not many studies on the practice of a technique and its replication.

For years I accompanied them and I had the opportunity to learn their techniques. Each time I spoke with them, I was surprised by their profound knowledge, their exacting analysis, their efforts, dedication and perseverance in order to decipher each particular technique. It was a path of great concentration and solitude during decades. ${ }^{9}$

a)

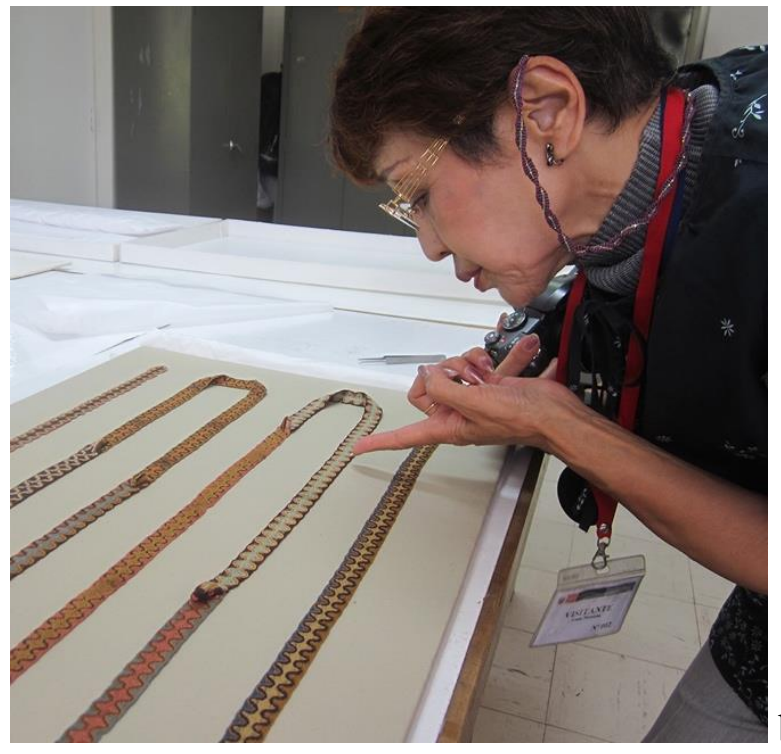

Figure 1. a) Yoshie Aoyagi in the MNAAHP. ${ }^{10}$ b) Keiko Watanabe in the MNAAHP. Photo Yuki Seo

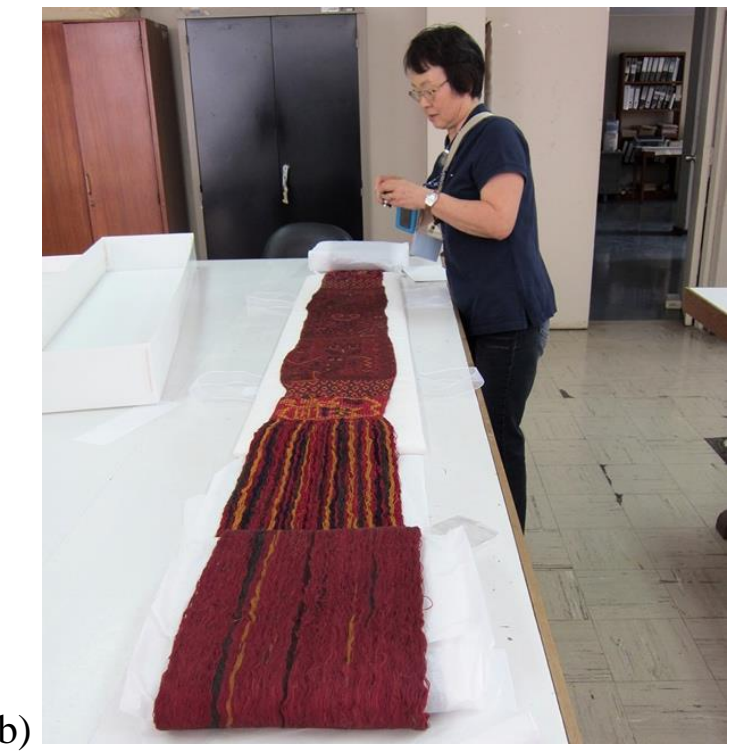

The beginning of the project:

In my personal experience, while I worked as a conservator, I began to analyze and practice the techniques with the clear intention of giving courses and spreading knowledge of the ancestral techniques.

\footnotetext{
${ }^{7}$ Watanabe calls this knotting technique Simple Knotting, following Emery. However, the structure is not open knotting like that used for nets. Irene Emery, The Primary Structures of Fabrics (Washington, D.C.: The Textile Museum, 2009), 34.

${ }^{8}$ Knotting of the Paracas period was developed between about 400 BC and AD 100. (Ann H. Peters, "Paracas knotted textiles and their cultural associations" in Watanabe 2020).

${ }^{9}$ Each master teacher has carried out 30-50 years of investigations.

${ }^{10}$ Museo Nacional Arqueología, Antropología e Historia del Perú.
} 
However, each textile technique requires a great deal of effort and study to reach a good level of skill. All the teachers and specialists demonstrated to me a long path of many years to attain a level of skill comparable to that of the prehispanic period. They each have spent three or four decades in research and said that they still needed much more to know and understand the profound world of each technique. After getting to know them, I was conscious that I would not be able to learn and develop all the techniques that interested me.

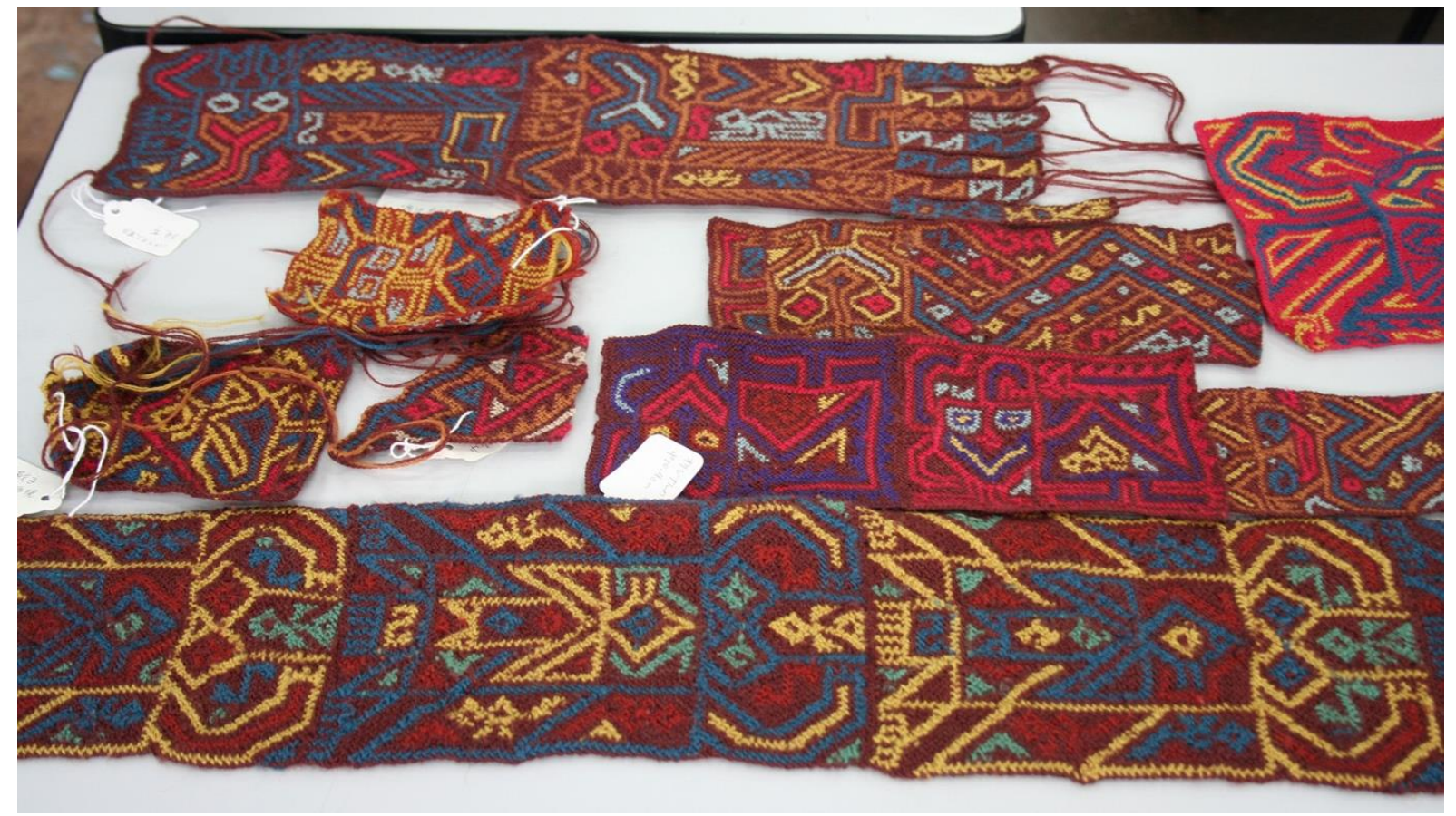

Figure 2. Replicas of Paracas knotting by Keiko Watanabe. Photo Yuki Seo.

One day I thought of our great fortune to now have a teacher of Paracas knotting after 2000 years. As she is an elder woman, this awakened in me a desperate concern and I asked myself: With her assistance, could we give back this technique to its people of origin, or might we lose her knowledge and hope that someone else might appear after another 2000 years?

I did not wish to lose this understanding and wished that this technique might be reborn anew in Peru. I decided to begin this project on a very hot day in February of 2016 in the garden of a friend's house, ${ }^{11}$ very close to the prehispanic sanctuary of Pachacamac.

Course and workshop in the Pontificia Universidad Católica del Perú (PUCP):

Although I was determined to do it and very clear about its importance, I did not know how to develop the courses, as I was a person who only had a great desire to achieve this, but I did not have access to the logistics. I knocked on the doors of government institutions, museums, large companies... nonetheless, I was unable to receive a positive response.

\footnotetext{
${ }^{11}$ Mr. Juan Arce and Mrs. Rocío Lanao, founders of Atinchik in Pachacamac, Lima, Peru.
} 
After more than a half year of this struggle (and I almost gave up), I had the opportunity to meet some professors at the PUCP who were researchers ${ }^{12}$ in the AXIS Arte program. In reality, at that moment I no longer had the hope of hearing a good response. I showed them, as always, my course plan and I explained to them the importance of this project as I had explained it to other entities.

As soon as I finished showing them my plan, they told me that we could hold a techniques workshop in the following month, during an event organized by AXIS Arte.

That day I felt that finally the door had opened for me to be able to begin this rebirth of the prehispanic techniques. It was a memorable day.

In November 2016, I gave my first workshop ${ }^{13}$ on two techniques, "The first steps of two ancestral techniques: Three-dimensional looping and Paracas knotting" in the V Encounter among Artists, Artisans and Designers, the event organized by AXIS Arte in PUCP.

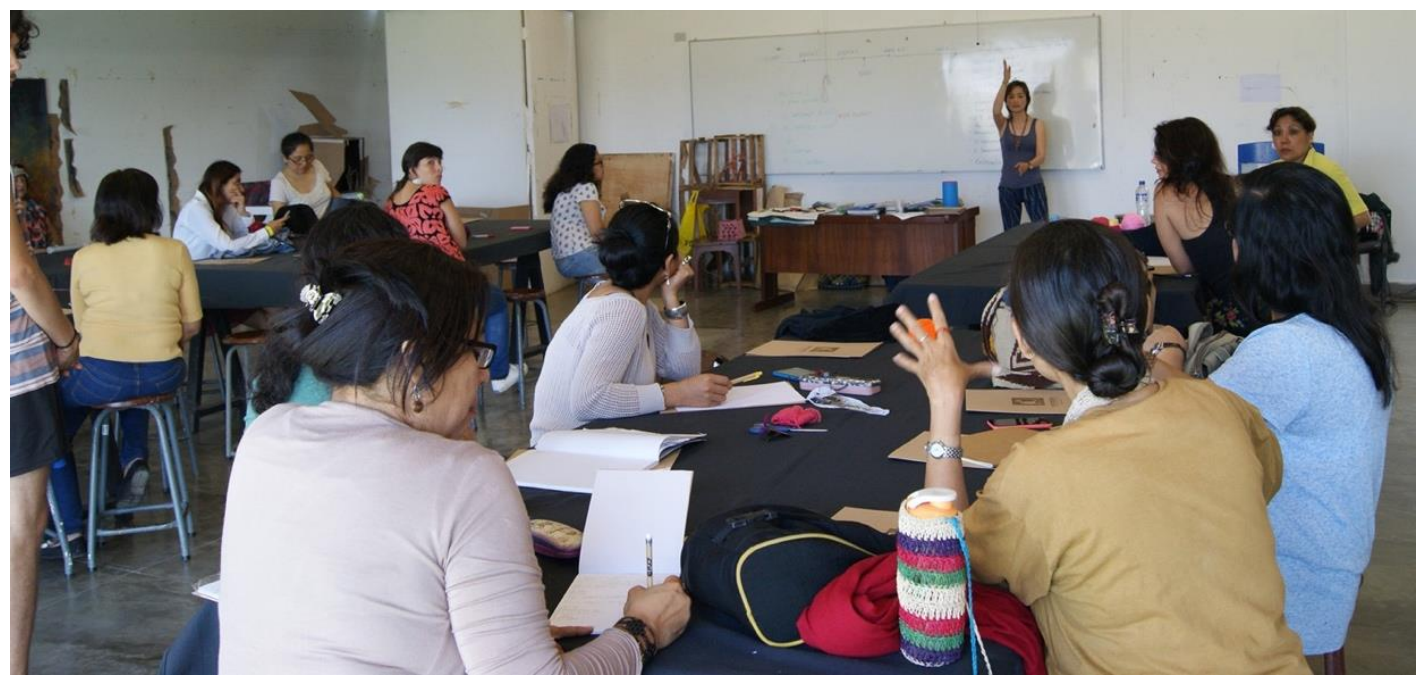

Figure 3. The first workshop in 2016 in the PUCP. Photo Justine Lamarche

Since the workshop was successful, I organized more courses ${ }^{14}$ and activities in the Faculty of Art and Design, with support from AXIS Arte:

- February 2017: Three-dimensional and flat crossed looping, organized by Yuki Seo

- June 2017: Three-dimensional and flat crossed looping, organized by Yuki Seo

\footnotetext{
${ }^{12}$ Professors of the Faculty of Art and Design, Edith Meneses, Pilar Kukurelo, and Luz Marina Hermoza of AXIS Arte PUCP, Group for applied research for development.

${ }^{13}$ A total of 30 participants and I had 4 assistants; Gabriela Ponce de León, Saki Yamamori, Fiorella Gonzales and Iván Ramírez. They are textiles teachers and researchers, and were previously trained.

${ }^{14}$ Each course consisted of theory, practice and analysis of original pieces in visits to museums.
} 
- July-August 2017: Brocade and crossed-warp tubular weave, ${ }^{15}$ with the invited professor Yukiko Tsukuda (Koyun) ${ }^{16}$

- March 2018: Basic and intermediate Paracas knotting with Keiko Watanabe

- February 2019: Basic, intermediate and advanced Paracas knotting, with Keiko Watanabe

- October 2020: Publication of the e-book Reconstrucción de un turbante Paracas realizado con la técnica de anudado simple ${ }^{17}$ by Keiko Watanabe, under the auspices of the Department of Art and Design of the PUCP and AXIS Arte.

- December 2020: Group presentation in the IX Encounter among Artists, Artisans and Designers. $^{18}$

a)

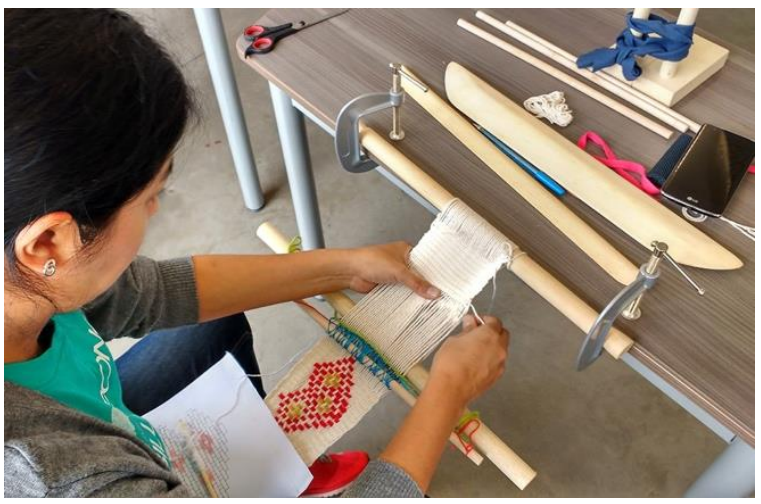

b)

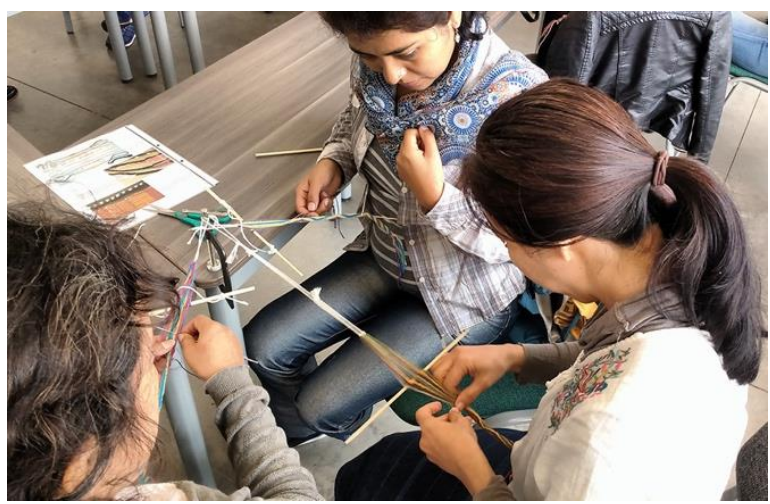

c)

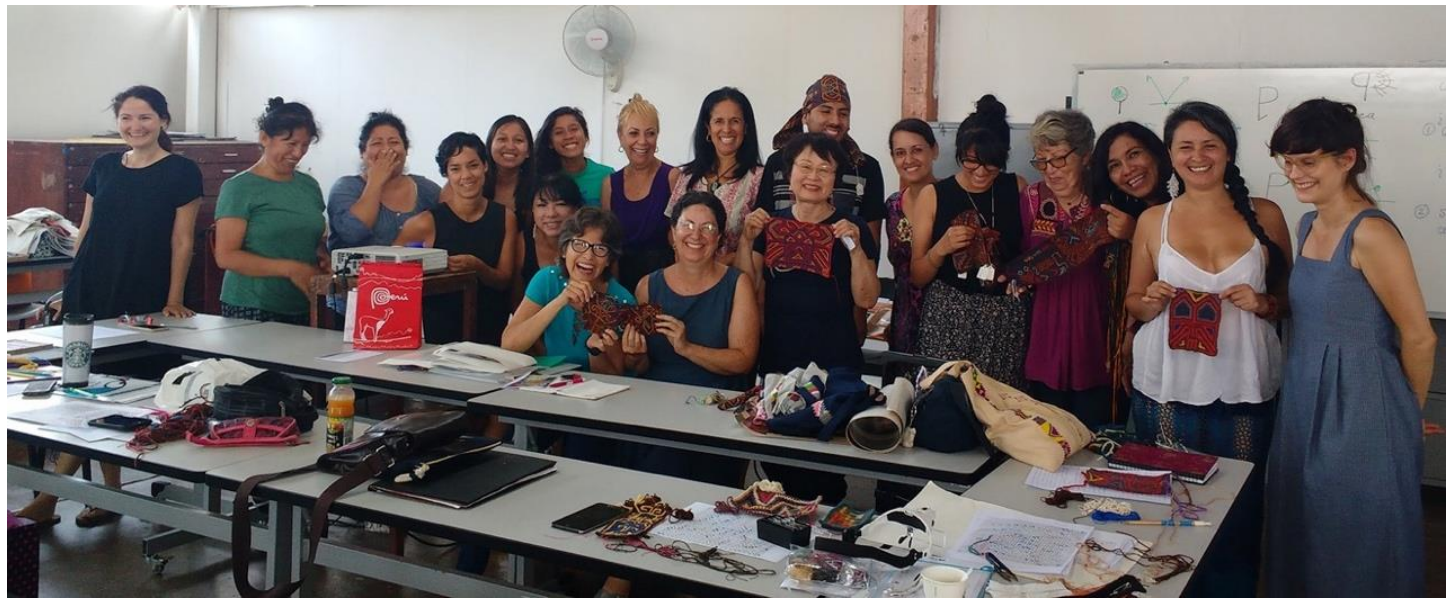

Figure 4. a) Brocade in 2017. b) Crossed-warp tubular weave in 2017.

c) Paracas knotting in 2019. Photos Yuki Seo

On the investigation of the Paracas knotting technique by Keiko Watanabe

\footnotetext{
${ }^{15}$ The name of this technique was defined with assistance from Soledad Hoces de la Guardia. At the time we called it the Chiribaya technique because the pieces are associated with the Chiribaya culture.

${ }_{16}$ Researcher and textile professor in Japan specializing in Kilim and textiles of Turkey, Guatemala and the Andes.

${ }^{17}$ The book is digital, available at https://doi.org/10.18800/978-612-47501-2-0.

$18 \mathrm{https://departamento.pucp.edu.pe/arte-y-diseno/evento/ix-encuentro-entre-artistas-artesanos-y-disenadores-}$ edicion-virtual-axis-20/
} 
One of the goals of this project was to demonstrate the profound work of Ms. Keiko Watanabe. Born in Japan in 1941, she lived for 25 years in the Republic of the Philippines because of her husband's work there. During her stay in that country, she had the opportunity to analyze the knotting used in women's dresses of the Maranao people. This knotting technique was used to join two cloths: however, it was no longer possible to find a weaver who could do it. After five years of analysis, she was able to reproduce its structure and technique. ${ }^{19}$

During 1989-1990, Japan's National Museum of Ethnology hosted an exhibition ${ }^{20}$ in which about 735 Peruvian prehispanic archaeological pieces were displayed, including an example of Paracas knotting from the Amano Museum in Lima. Ms. Keiko Watanabe saw it and was quite excited to find a technique based on knots. She asked the museum exhibition director for permission to analyze the piece, as she realized that the structure of this textile was quite similar to the technique that she had researched and analyzed in the Philippines. A principal difference between the Philippine knotting and that of Paracas is that the former unites two cloths and the Paracas knotting is created as an independent panel.

There began her path to Peru. In that moment, she was 50 years of age.

She took photographs of the original piece, she enlarged them to the largest scale that she could and began to count the knots and draw them in a gridded notebook. Then she created a diagram with an index that she formulated and proceeded to make a replica sample. (She continues to use this method today.)

At first glance, it may seem quite easy to decipher the technique. However, it was very complicated in the beginning, because a key factor was missing to be able to start the process: the first knot. In Paracas knotting there is not an apparent directional order, neither from below to above, nor from left to right. The search for the first knot lasted nearly a year.

At last, after two years of work she achieved one sample, a panel and a part of the border, ${ }^{21}$ and by the end of another year she finished the piece. The process of reconstruction of this piece has been documented and written up step by step, in great detail, creating the book noted above, published in 2020 only a few days before the TSA symposium.

After creating the replica of this piece from the Amano PreColumbian Textile Museum, Ms. Watanabe began to look for similar pieces in other museums. She travelled several times to the United States as well as to Peru.

On each trip, she obtained permission to take photographs of the pieces and make the replicas. Once she had carried out the analysis, created the diagram and made two samples, she returned

\footnotetext{
${ }^{19}$ There is an essay about this research but it is still unpublished.

${ }^{20}$ Exhibit and catalogue: Gran Civilización de los Andes (Osaka, The Asahi Shimbun, 1989). The exhibition traveled among several large cities in Japan for two years.

${ }^{21}$ This piece consists of five main panels with the image of a bird and the two borders with a zigzag design.
} 
with them and donated one replica with her analysis and documentation to the museum so that future researchers could use her replication process as a starting point for future studies. The Textile Museum and George Washington University Museum and several museums in Peru hold an archive created during her research.

By December 2020, Keiko Watanabe had replicated 24 pieces, and was in the process of analyzing a new piece which will be number 25 .

Ms. Watanabe has held courses with the participation of more than 30 persons each year. When the participants are just beginning to learn the knotting technique and see the replicas made by Keiko, they are deeply surprised and filled with admiration for this researcher.

I confess that I have been one of them. When one realizes how difficult it is to achieve a replica, even though we already have the analytic diagram step by step for each of them, only then we can imagine her long and solitary path. Also, at that point almost everyone asks her what has inspired her to do this, why she continues, being a woman who does not belong to any institution. Where does this immense passion come from, this desire to decipher an ancient technique from another country so distant from her own culture?

a)

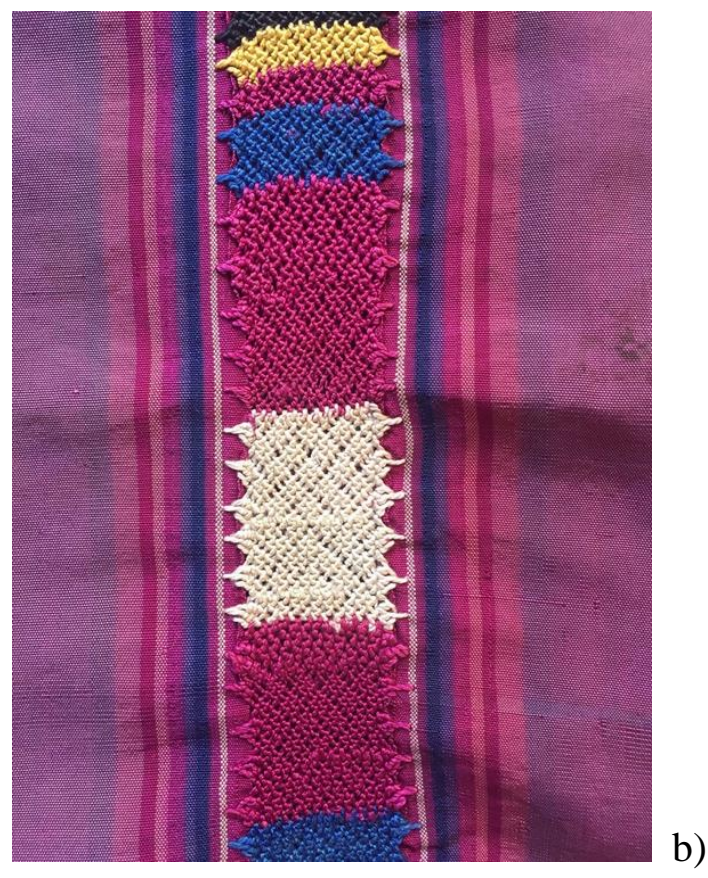

b)

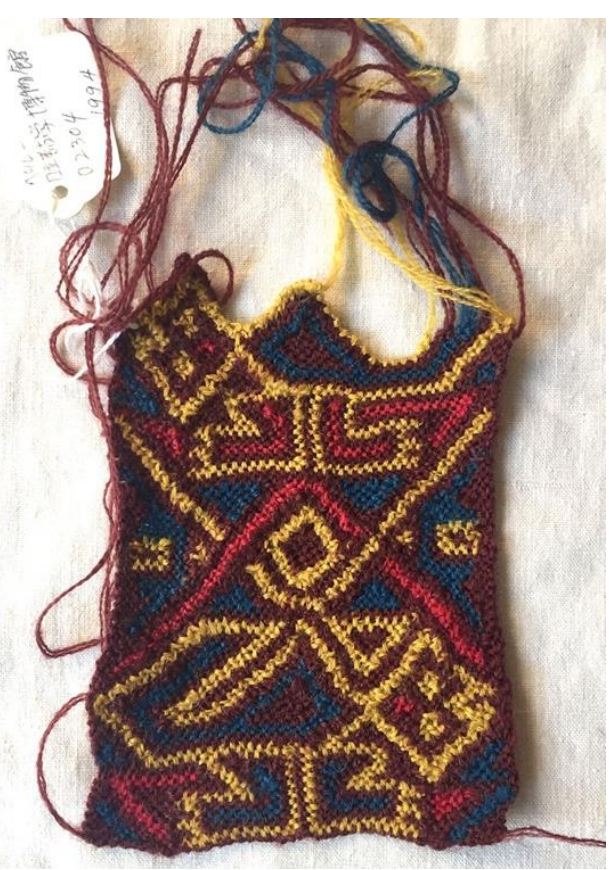

Figure 5. a) A section of Filipino knotting, with the two adjacent cloths. b) Paracas knotting, in the process of reconstructing a piece in the MNAAHP, RT 02304. Photos Yuki Seo.

She comments to us that this technique of the Paracas culture based on knots is very unique. She has told us, "I perceive that the piece has been made by persons or groups who are highly specialized. The designs are very complex and moreover I have discovered that some pieces have been restored by persons of the Paracas culture itself, and I can note that there are some pieces that had been used for more than a hundred years, submitted to constant repairs. These 
were sacred objects used in the burials or perhaps they also had been used for very important ceremonies. I wished to know how they had made them. It was very difficult in the beginning, but I did not give up because I knew that this piece had been made by a human being like myself, it had been made by someone's hands 2000 years ago. Therefore, why would I not be able to do it? Of course, I also could. To analyze, look for and follow the steps of this technique made me understand and feel their life, and the nature of their community and the society of that time. I can see what was important to their life and in the social world of the Paracas culture."

\section{Participants y results of the courses}

The majority of the participants in the courses held in the PUCP were adults and already professionals, such as visual artists, school teachers, archaeologists, ceramists, jewelers, and a professor of textiles and embroidery. After the first courses on three-dimensional and flat crossed looping, the participants began to apply this technique in their own work. They organized individual or group exhibits, which led some to win awards for presenting new historic concepts related to their own identities.

My course design had the participants develop one piece, the replica. However, the artists and teachers expanded the possibilities for use of an ancestral technique, employing diverse materials and concepts.

Here I share some projections and initial results of these two techniques, three-dimensional and flat crossed looping and Paracas knotting. Many of the participants continue to work with them and with other techniques such as brocade and crossed-warp tubular weave.

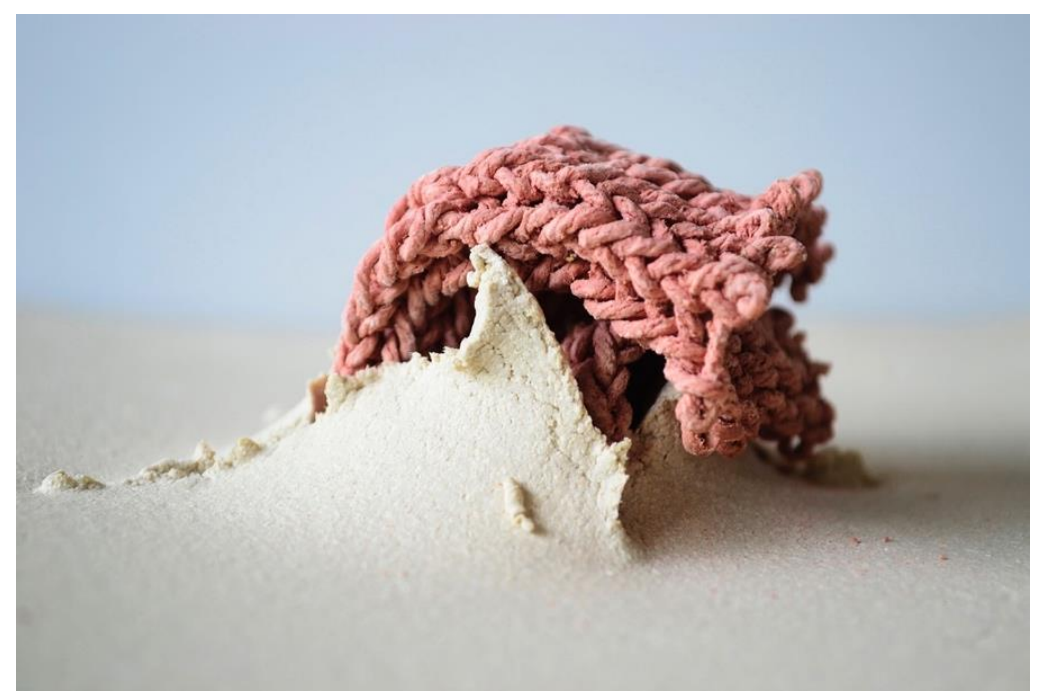

Figure 6. Ivet Salazar, visual artist. She transfers a textile structure to a ceramic medium. ${ }^{22}$ Photo Ivet Salazar.

\footnotetext{
${ }^{22}$ We have recently communicated with professor Mau Macedo of Okayama Prefectural University, in Japan. He also has a student working on textile structures in a ceramic medium.
} 


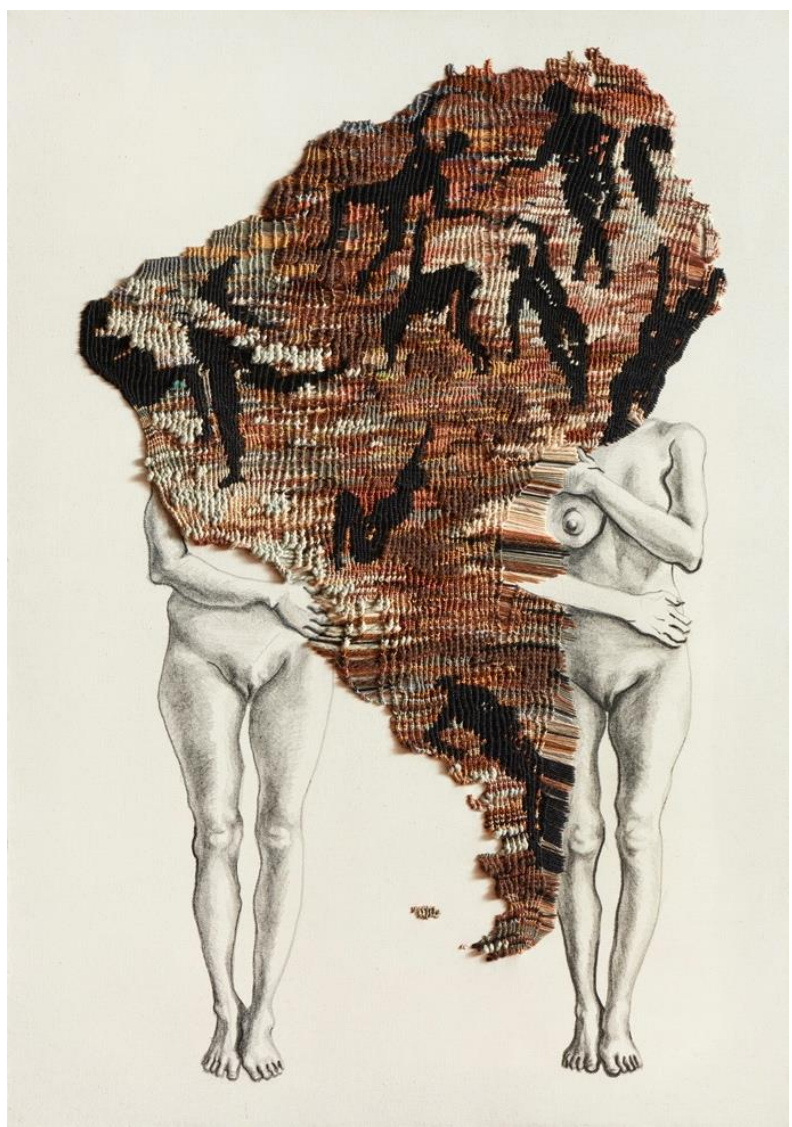

Figure 7. Romina Chuls, visual artist. She is using flat looping with charcoal on canvas. Photo Romina Chuls.

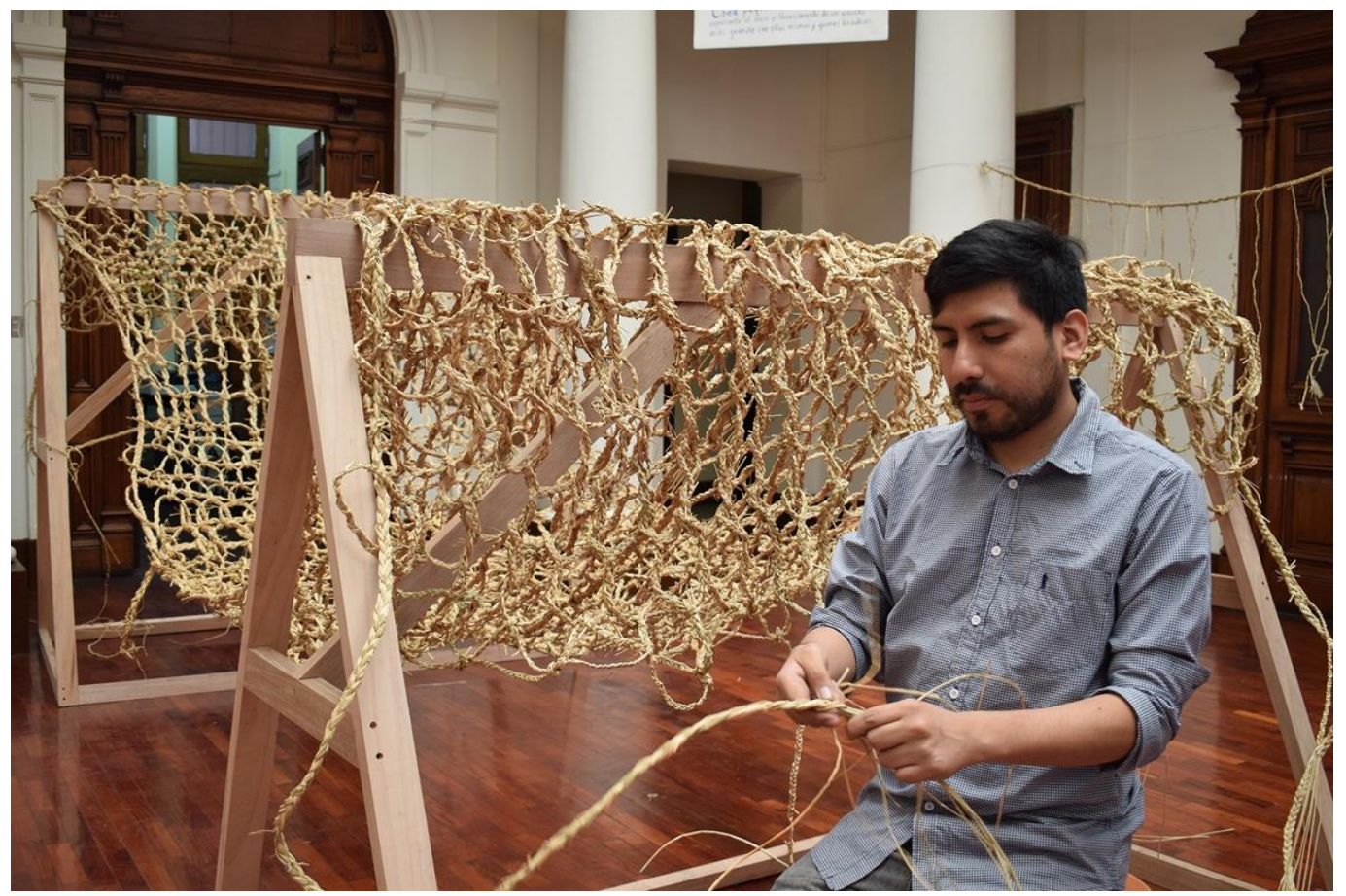

Figure 8. Henry Ortiz, visual artist. He researches textile techniques of the Archaic or preceramic period in Peru and the use of prehispanic raw materials. Bulrushes (Scirpus americanus) have been used in this work. Photo Henry Ortiz. 


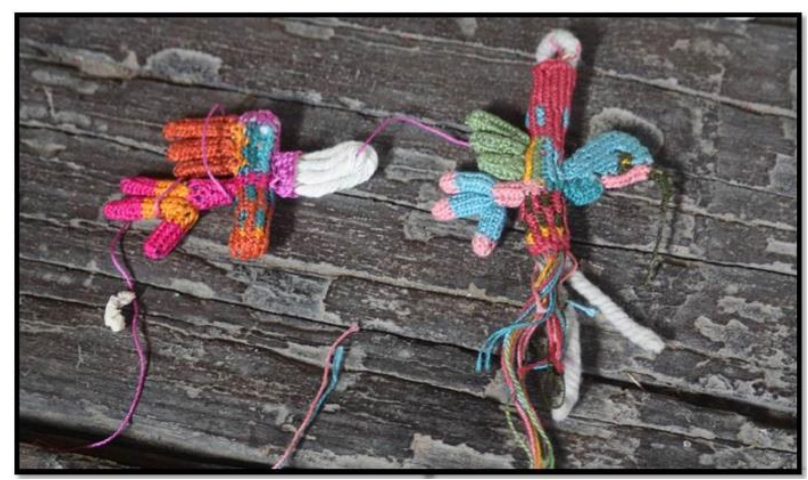

Figure 9. Nora Carrasco, visual artist. She works with the communities of the Amazon, linked to ancient and current traditions, to develop new artisan products that she presents to the market. Photo Nora Carrasco.

Another objective of the project was to teach these techniques to hand weavers in various regions of Peru. In March of 2019, Ms. Keiko Watanabe and I went to Cusco to teach a course in Paracas knotting for the weavers of the Center for Traditional Textiles of Cusco (CTTC). Thanks to the founder, Nilda Callañaupa, we have been able to appreciate a wide range of prior skill sets and different learning strategies. The textile masters of the Cusco region did not need to see the diagram, instead they simply watched Ms. Watanabe's hands in order to learn the knotted technique.

Rubén Espirilla Quispe was one of the participants and he continued to practice the knotted technique. This young weaver has been able to make samples and replicas of several original pieces. His level of talent and interest is impressive.

a)

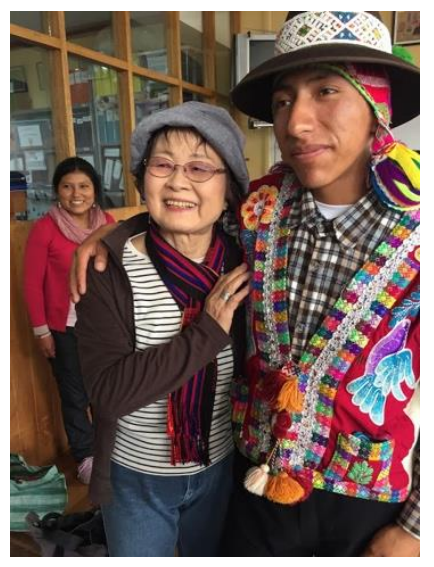

b)

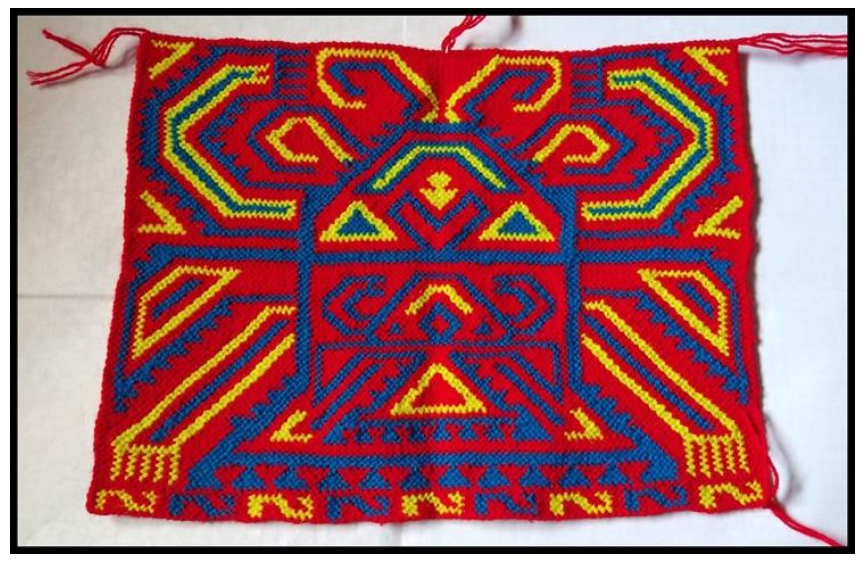

Figure 10 a) Keiko Watanabe with Rubén Espirilla. Photo Yuki Seo. b) Replica of part of RT 0333, MNAAHP, made by Rubén Espirilla, 2020. Photo Rubén Espirilla.

Another result has been the application of the knotted technique in artistic projects in classes on art and culture in a public high school in the Santiago de Surco district of Lima, José María Arguedas school, organized by professor Arturo Nery Segura. 
Mr. Nery took the course in basic Paracas knotting and based on that experience he incorporated the practice of this technique in his curriculum, beginning in 2018 and continuing today. Currently more than 300 high school students are practicing Paracas knotting. The yearly display of their artistic projects is testimony to their efforts and the challenge they have met.

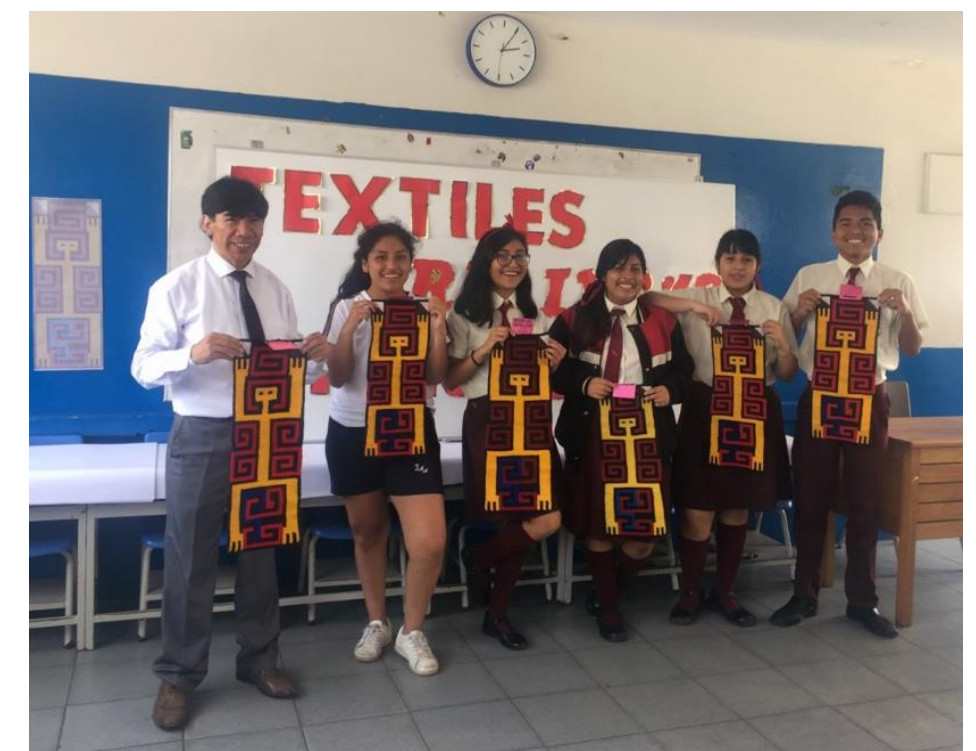

Figure 11. Professor Arturo Nery with his students in the 2019 annual presentation. Photo Arturo Nery

The path continues:

During these years, whenever I had the opportunity to present this project, I always say to those present: "A people without their culture is like a library without books. Five hundred years ago, Peru lost several books. I would like these to be returned to that great library."

Although they are only a few, I consider that putting these techniques into practice is as if we were returning those books, and that moreover it is as if the young students may be beginning to read them.

In the beginning, it seemed that the project was very simple. I only wished to recover the technique. Nonetheless, we have realized that this manual activity of recovering the technique, is not only learning a way to create a textile, it is also a way to perceive society, to touch the sentiment of the weavers, and to look more deeply at the way of thinking and the philosophy of that ancient time. The time dedicated to the practice of prehispanic textiles has another value, which is not comparable to the commercial modern time in which we presently find ourselves.

Now, we can say that to recover techniques is not only to practice techniques which have been lost, rather it is a rebirth of the culture and thought of prehispanic times. It is to comprehend the coherent sense, the integral system of that period. It makes me think that to make something with our hands, be it textile or ceramic, is the only way to recognize the sense of time in that epoch. 
It was a seed, and I believed that it would be like the seed of a plant. I did not imagine what result it would have, yet several flowers of various colors are sprouting. They have given me many surprises and much delight.

This project continues, with further projections and diverse challenges. I hope that the next chapter may include more stories about teachers and more techniques reborn in our present times.

\section{Acknowledgements:}

This project has required much help from many persons from its beginnings until today. I have been able to get to know an enormous number of professionals, organizers, teachers and participants. It is impossible to name each one of them, however, I am thankful for their work and their support. Thus, I express my thanks to my coworkers in conservation and archaeological friends who made it possible for me to analyze pieces and who shared their opinions and observations. To the professors and the PUCP team for their constant support in organizing the courses, to Jessica Kea for technical support in the digital aspects, to Iván Ramírez for insights into Andean thought, and to professor Betty Olivos for text editing, my deepest thanks.

My sincere gratitude to the teachers from Japan, to Yoshie Aoyagi, Keiko Watanabe, Makiko Tada, Chieko Aihara, Kanae Hayauchi, the Tokyo University group, and that great master who has left us with her book, Miyako Suzuki. To Yukiko Tsukuda (Koyun) for constant support, for technical advice and for sharing knowledge.

For fostering participation in the 2020 Biennial Symposium of the Textile Society of America, I cannot fail to mention the support of Dr. Ann H. Peters. She demonstrated great professionalism in achieving this goal, building our participation as a group through Saturday meetings where we explored interesting textile topics. Her constant support and great patience were vital in preparing both the presentation and this publication.

In participating in the session "Dialogues between archaeological, historical and contemporary textiles in the Andes", I became familiar with the academic achievements of Latin American professionals, Verónica Cereceda, Soledad Hoces de la Guardia and Bárbara Cases, as well as those of my Peruvian friends, Adriana Soldi, María Elena del Solar y Rommel Ángeles Falcón, with whom each conversation was the equivalent of a master class in textiles.

I express my gratitude and admiration for today's master weavers and those of the past, who accompany me in following this path. 


\section{Bibliography}

Aihara, Chieko. Sprang. Kanagawa: Yupanqui kobo, 2003.

https://sites.google.com/site/ypq2aiharaes2/

Aoyagi, Yoshie. Exploring the Braids of the Andes. Tokyo: Texte, 2020.

Emery, Irene. The Primary Structures of Fabrics. Washington, D.C.: The Textile Museum, 2009.

Kajitani, Nobuko. The Textiles of the Andes: Senshoku no Bi (Textile Art). Kyoto: Kyoto Shoin, Fall 1982.

Suzuki. Miyako. Organizational skills and techniques of woven textiles of the Andes. Kyoto: Shikosha, 1999.

Tada, Makiko. (2004) “Andean Braids," Comprehensive Treatise of Braids II, Tokyo: Texte, Inc., 2004.

Tada, Makiko. "Braids of the Andes," Advances in Kumihimo and Fiber Arts: Proceedings of the Fourth International Conference on Braiding Braids 2019, 51-58.

Watanabe, Keiko. Reconstrucción de un turbante Paracas realizado con la técnica de anudado simple. Department of Art and Design of the PUCP and AXIS Arte.

https://doi.org/10.18800/978-612-47501-2-0. 